\title{
Molecular phylogeny of the Cricetinae subfamily based on the mitochondrial cytochrome $b$ and 12S rRNA genes and the nuclear vWF gene
}

\author{
Karsten Neumann ${ }^{\mathrm{a}, *}$, Johan Michaux ${ }^{\mathrm{b}, *}$, Vladimir Lebedev ${ }^{\mathrm{c}}$, Nuri Yigit ${ }^{\mathrm{d}}$, \\ Ercument Colak ${ }^{\mathrm{d}}$, Natalia Ivanova ${ }^{\mathrm{e}}$, Andrey Poltoraus ${ }^{\mathrm{e}}$, Alexei Surov ${ }^{\mathrm{f}}$, Georgi Markov ${ }^{\mathrm{g}}$, \\ Steffen Maak ${ }^{\mathrm{h}}$, Sabine Neumann ${ }^{\mathrm{a}}$, Rolf Gattermann ${ }^{\mathrm{a}}$ \\ a Institute of Zoology, Martin-Luther-University Halle-Wittenberg, Domplatz 4, D-06108 Halle (Saale), Germany \\ ${ }^{\mathrm{b}}$ Unité de Recherches Zoogéographiques, Institut de Botanique (Bat. 22), Boulevard du Rectorat, Université de Liège, 4000 Liège (Sart Tilman), Belgium \\ ${ }^{\mathrm{c}}$ Zoological Museum, Moscow State University, Russia \\ ${ }^{\mathrm{d}}$ Department of Biology, Faculty of Science, University of Ankara, O6100 Beşevler, Ankara, Turkey \\ ${ }^{\mathrm{e}}$ Engelhardt Institute of Molecular Biology, RAS, Moscow, Russia \\ ${ }^{\mathrm{f}}$ Severtzev Institute of Animal Ecology and Evolution, RAS, Moscow, Russia \\ ${ }^{\mathrm{g}}$ Institute of Zoology, Bulgarian Academy of Sciences, Sofia, Bulgaria \\ ${ }^{\mathrm{h}}$ Institute of Animal Breeding and Husbandry with Veterinary Clinic, Martin-Luther-University Halle-Wittenberg, Adam-Kuckhoff-Str. 35, \\ D-06108 Halle (Saale), Germany
}

Received 14 June 2005; revised 23 December 2005; accepted 9 January 2006

Available online 17 February 2006

\begin{abstract}
Despite some popularity of hamsters as pets and laboratory animals there is no reliable phylogeny of the subfamily Cricetinae available so far. Contradicting views exist not only about the actual number of species but also concerning the validity of several genera. We used partial DNA sequences of two mitochondrial (cytochrome $b, 12 \mathrm{~S}$ rRNA) and one partial nuclear gene (von Willebrand Factor exon 28) to provide a first gene tree of the Cricetinae based on 15 taxa comprising six genera. According to our data, Palaearctic hamsters fall into three distinct phylogenetic groups: Phodopus, Mesocricetus, and Cricetus-related species which evolved during the late Miocene about 7-12 MY ago. Surprisingly, the genus Phodopus, which was previously thought to have appeared during the Pleistocene, forms the oldest clade. The largest number of extant hamster genera is found in a group of Cricetus-related hamsters. The genus Cricetulus itself proved to be not truly monophyletic with Cricetulus migratorius appearing more closely related to Tscherskia, Cricetus, and Allocricetulus. We propose to place the species within a new monotypic genus. Molecular clock calculations are not always in line with the dating of fossil records. DNA based divergence time estimates as well as taxonomic relationships demand a reevaluation of morphological characters previously used to identify fossils and extant hamsters.
\end{abstract}

(C) 2006 Elsevier Inc. All rights reserved.

Keywords: Cricetinae; Cytochrome $b$; Hamster; Phylogeny; von Willebrand factor; $12 \mathrm{~S}$ rRNA

\section{Introduction}

The subfamily Cricetinae comprises a group of mouseto rat-sized rodents with characteristic cheek pouches and

\footnotetext{
${ }^{*}$ Corresponding authors. Fax: +49 3455527624 (K. Neumann).

E-mail addresses: karsten.neumann@zoologie.uni-halle.de (K. Neumann), michaux@ensam.inra.fr (J. Michaux).
}

short tails. Important dental characteristics distinguishing extant Cricetinae are brachydont cuspidate molars with conspicuously bifurcated anterocones, an absent or reduced mesoloph and upper M1, M2 with four roots. Most hamster genera are described from the late Miocene and peaks in species diversity seem to coincide with cooler periods during the following Plio- and Pleistocene (Argyropulo, 1938; Kowalski, 2001; McKenna and Bell, 1997). 
Hamsters are semi-fossorial and live mainly solitary. They inhabit steppe and semi-arid habitats as well as agricultural land throughout the Palaearctic. Some hamster species show occasional gradations and are persecuted as pests in crop lands. Two species, the golden hamster Mesocricetus auratus and the Chinese hamster Cricetulus griseus are important laboratory animals for biological and medical research.

The origin of Cricetinae is often associated with Democricetodontini (sometimes included in Megacricetodontini) a widely distributed tribe in the northern hemisphere during the early and middle Miocene (Fahlbusch, 1969). The relationships of Cricetinae with some other Neogene lineages which share characters of voles and hamsters such as Microtocricetinae and Ischymomyinae remain unclear.

Genetic studies of hamster taxonomy are mainly restricted to cytological (e.g., Gamperl et al., 1978; Matthey, 1960; Radjabli, 1975) and allozyme studies (Kartavtsev et al., 1984a,b). There is a fair amount of morphological data about the group (e.g., Vorontsov, 1982) but they do not provide enough reliable synapomorphies for phylogenetic inference. In this respect, the reconstruction of ancestral lines of extant hamster species on the basis of fossils proves complicated and often questionable (Hir, 1997; Kowalski, 2001). The current systematics of the subfamily is confusing and the actual number of species as well as the phylogenetic relationship between genera is highly disputed (e.g., Corbet, 1978; Wilson and Reeder, 1993). Mouse-like hamsters of the genus Calomyscus are occasionally considered as Cricetinae (Corbet, 1978; Pantelejev, 1998) but morphological, cytological (Matthey, 1961), and genetic data (Michaux et al., 2001; Steppan et al., 2004) disprove such a view. For that reason we excluded Calomyscus from analyses. Our study aimed to provide a first genetically based systematic framework for the Cricetinae examining a representative number of spe- cies. Furthermore, we evaluated the controversial position of taxa like Allocricetulus and Tscherskia and attempted to resolve the phylogenetic relationship of extant hamster genera.

\section{Material and methods}

\subsection{Animal material}

This study includes samples of 15 hamsters mainly collected in their natural distribution area (Table 1). Only Cricetulus griseus, Phodopus roborovskii, Phodopus sungorus, and Phodopus campbelli were obtained from laboratory strains kept at the Institute of Zoology, Martin-LutherUniversity Halle-Wittenberg, Germany and Severtzev Institute of Animal Ecology and Evolution in Moscow, Russia. Distribution ranges of the analysed species are described in Fig. 1. DNA data were usually obtained from the same individual except for a few species where genes had been sequenced from two individuals belonging to different populations. Such animals and genes are marked in Table 1.

\subsection{DNA sequencing of cytochrome $b, 12 S r R N A$ and von Willebrand Factor exon 28}

DNA was extracted from ethanol preserved or fresh tissues following a standard protocol supplied with the E.Z.N.A. Tissue DNA Kit II system (peqlab Biotechnologie). Gene amplification was carried out using the ReadyTo-Go-system (Amersham). Forty pmol of each primer and $0.2 \mu \mathrm{g}$ of genomic DNA were added to a total volume of $50 \mu \mathrm{l}$. PCR was run in a thermocycler UNO II, Biometra employing 35 cycles $\left(60 \mathrm{~s}\right.$ at $94{ }^{\circ} \mathrm{C}, 60 \mathrm{~s}$ at primer specific annealing temperature and $90 \mathrm{~s}$ at $72^{\circ} \mathrm{C}$ ) with an initial heating step of $4 \mathrm{~min}$ at $94{ }^{\circ} \mathrm{C}$ and a final extension cycle of $10 \mathrm{~min}$ at $72^{\circ} \mathrm{C}$.

Table 1

Hamster species used for DNA sequencing and their origins

\begin{tabular}{|c|c|c|c|c|}
\hline Species group & Genus & Species & Locality & Tissue \\
\hline \multirow[t]{9}{*}{ "Dwarf Hamster" } & Phodopus & P. roborovskii & Lab strain & Liver \\
\hline & Phodopus (?) & P. campbelli & Lab strain & Liver \\
\hline & & P. sungorus & Lab strain & Liver \\
\hline & Cricetulus & C. longicaudatus & Buriati/Russia & Liver \\
\hline & & C. barabensis* & Uur Gol/Mongolia; N. Khangai/Mongolia & Liver \\
\hline & & C. griseus & Lab strain & Liver \\
\hline & Cricetulus (?) & C. migratorius* & Kayseri, Central Anatolia/Turkey; Volgograd/Russia & Liver \\
\hline & Allocricetulus & A. eversmanni & Saratov region/Russia & Liver \\
\hline & Tscherskia & T. triton $^{*}$ & near Beijing/China; Ussuriisk reg./Russia & Liver \\
\hline \multirow[t]{5}{*}{ "Middle Hamster" } & Mesocricetus & M. raddei nigriculus & Mozdok, Ossetia/Russia & Liver \\
\hline & & M. raddei avaricus & Dagestan, Kunzakh/Russia & Liver \\
\hline & & M. auratus & Aleppo/Syria & Liver \\
\hline & & M. brandti & Central Anatolia/Turkey & Liver \\
\hline & & M. newtoni & Shumen/Bulgaria & Liver \\
\hline "Large Hamster" & Cricetus & Cr. cricetus $^{*}$ & Hakel, Saxony-Anhalt/Germany; Mozdok, Ossetia/Russia & Liver \\
\hline
\end{tabular}

Question marks indicated genera which are not supported by DNA data. * marks species with sequences obtained from animals of two different populations. 

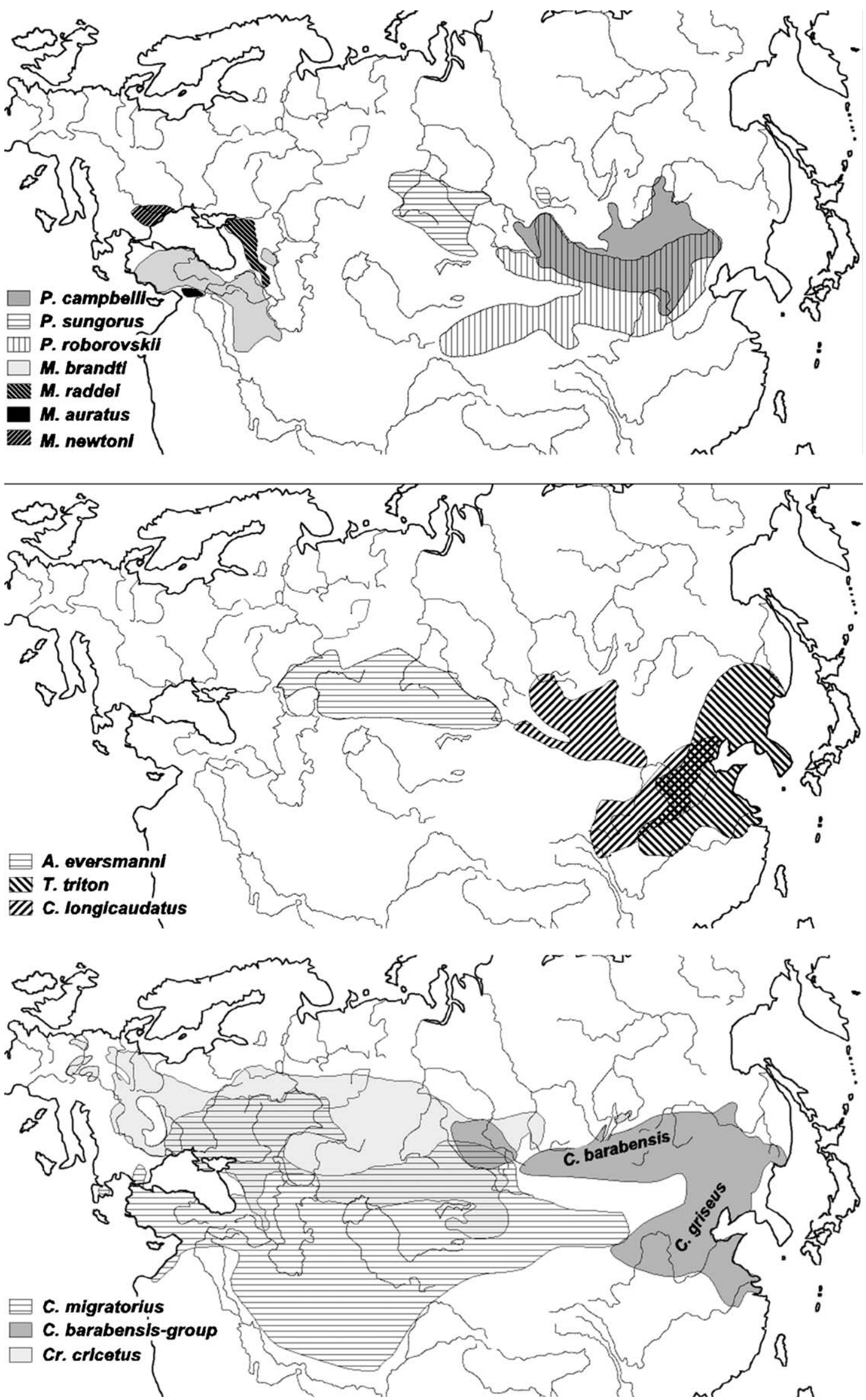

Fig. 1. Geographical distribution of sampled Cricetinae species. The maps are based on Panteleyev (1998) with revisions. Abbreviations are as follows: P, Phodopus, M, Mesocricetus, A, Allocricetulus, T, Tscherskia, C, Cricetulus, Cr, Cricetus. 
A large portion of cytochrome $b$ (cyt $b$ ) was amplified and sequenced as described in Neumann et al. (2005).

PCR and sequencing of the near complete $12 \mathrm{~S}$ rRNA (12S) was achieved according to the procedure given in Kuznetsov et al. (2001) using the following PCR primers: Phe389L: 5'-GGCACTGAAAATGCCTAGATG-3', 1379H: 5'-CCAAGCACACTTTCCAGTATG-3', 842L: 5'-CAAACTGGGATTAGATACC-3', 1015H: 5'-GGT [G/A]AGGT[T/C]TATCGGGG-TTT-3', 860H: 5'-GGT ATCTAATCCCAGTTTG-3' and L329: $5^{\prime}$-AAAGCA AAGCACTG-AAAATG-3'/H618: 5'-TATCGATTATA GAACAGGCTCC-3'.

Amplification and sequencing of von Willebrand Factor (vWF) exon 28 followed Huchon et al. (1999).

\subsection{Sequence alignment and saturation analysis}

Partial genes were compared to published genes (GenBank) to confirm gene identity. New sequences were aligned with the ED editor (MUST package; Philippe, 1993). The program AFAS (MUST package) was used to combine the aligned matrices of cyt $b, 12 \mathrm{~S}$, and $\mathrm{vWF}$.

All three genes were examined for saturation following Philippe and Douzery (1994) and Hassanin et al. (1998). Using the matrices of patristic and adjusted character distances calculated by PAUP* 4.0b8 (Swofford, 1998), the pairwise numbers of observed differences were plotted against the corresponding values for inferred substitutions. The slope of the linear regression (S) was used to evaluate the level of saturation. When no saturation is observed in the data set, the slope equals one whereas the slope tends towards zero as the level of saturation increases.

\subsection{Phylogenetic reconstructions}

The level of incongruence between genes was tested using PAUP* 4.0b8 (option Hompart). This approach uses the incongruence length difference (ILD) test with the parsimony criterion; 1000 randomizations were performed on variable sites only (Farris, 1985).

As the ILD test showed a high congruence between the three studied genes (see below for details), phylogenetic analyses were performed using the combined matrix for cytb (924 bp), 12S (973 bp), and vWF (789 bp) sequences.

The aligned sequences were analysed by distance (neighbour joining, NJ; Saitou and Nei, 1987), maximum parsimony (MP) (Fitch, 1971), and maximum likelihood (ML) methods using PAUP* 4.0b8. Model test version 3.06 (Posada and Crandall, 1998) was used to determine the best-fit substitution model for the Cricetinae data. According the results of this test (using the AIC criteria), the General Time Reversible (GTR) model was used for the distances and ML analyses. To take into account differences of substitution rates across sites, the GTR analysis was performed assuming a gamma distribution at eight categories. The alpha parameter (Yang, 1996) and the proportion of invariant sites (I) were estimated with the ML method in
PAUP* 4.0b8. MP analyses were performed using heuristic search and TBR branch swapping option.

The robustness of inferences was assessed by bootstrapping (BP) (1000 random repetitions for MP and distance analyses, and 100 for ML).

A Bayesian approach to phylogeny reconstruction (Huelsenbeck et al., 2001; Yang and Rannala, 1997) was also used, implemented in MrBayes 3.1.1. (Huelsenbeck and Ronquist, 2001). Metropolis-coupled Markov chain Monte Carlo sampling was performed with four chains that were ran for 3 million generations, using default model parameters as starting values. Bayesian posterior probabilities were picked from the $50 \%$ majority rules consensus of trees sampled every 100 generations, after removing trees obtained before chains reached apparent stationarity ("burn in" determined by empirical checking of likelihood values). This analysis was repeated 10 times to check if the chains always converged on a similar distribution and if the corresponding results were the same. Finally, the analysis was performed with separate models for each gene. Each model of evolution was estimated using MrBayes 3.1.1.

\subsection{Molecular clocks and divergence time}

In order to determine divergence times within Cricetinae, we used two approaches. At first we applied a global clock to a linearized tree as described in Michaux et al. (2001). Secondly, we imposed a relaxed clock which allows for a heterogenous substitution rate according to Thorne et al. (1998). Both methods already produced overlapping results (Michaux et al., 2001; Steppan et al., 2004).

To apply a general clock we checked the assumption of rate constancy with the help of both relative-rate and likelihood-ratio tests. To test for rate differences of cyt $b, 12 \mathrm{~S}$, and vWF between the different Cricetinae genera, relative-rate tests were conducted with each of them against the remaining lineages. The relative-rate tests were done with RRTree, version 1.0 (Robinson et al., 1998) which improves the test of $\mathrm{Wu}$ and $\mathrm{Li}$ (1985) by taking into account taxonomic sampling and phylogenetic relationships. The three DNA regions were analysed separately. The ML tree for each gene was chosen as the reference topology. According to the muroid phylogeny obtained by Michaux et al. (2001) and Steppan et al. (2004), Cricetomys gambiana and Nesomys rufus were used as outgroups. For coding sequences (cytb, $\mathrm{vWF}$ ), relative-rate tests were performed on the proportions of synonymous (Ks) and non-synonymous (Ka) substitutions. For non-coding regions (12S), relative-rate tests were performed on the proportion of all the substitutions types (K). Likelihood-ratio tests were performed as proposed by Felsenstein (1981) for each gene separately and calculated in PAUP* $4.0 \mathrm{~b} 8$ using the ML tree for the combined data as the reference topology within Cricetinae. The outgroup comprised Cricetomys, Nesomys, Mus, Rattus, Tatera, Gerbillus, Clethrionomys, and Peromyscus (just the latter two for $12 \mathrm{~S}$ ); cladistic relationships between them were accepted as given in Steppan et al. (2004). 
We also estimated divergence times using the relaxed Bayesian clock method for multigene data (multidivtime program; Thorne and Kishino, 2002). The ML topology for the combined data were used as the reference tree. Only closest outgroups (Peromyscus and Clethrionomys) were included in the $12 \mathrm{~S}$ matrix due to ambiguities in alignments with sequences from distant taxa such as Cricetomys and Tatera. The F84 + G model was applied independently to each of the within-gene partitions such as codon positions for $\mathrm{vWF}$ and cytb or stems and loops for $12 \mathrm{~S}$. Model parameters were estimated with the use of baseml software (PAML version 3.14; Yang, 1997). Branch lengths and their covariance matrices were calculated with estbranche-dna program (Multidistribute package; Thorne and Kishino, 2002). Multidivtime program was run with the Markov chain sampled 10,000 times, every 100th generation. The burn in was set at 10,000 generations. The following prior distributions were accepted: $20 \mathrm{MY}$ $(\mathrm{SD}=20 \mathrm{MY})$ for the expected time between tip and root of the tree corresponding to the split between Murinae + Gerbillinae and Arvicolinae + Cricetinae + Peromyscinae lineages; $0.0075(\mathrm{SD}=0.040)$ substitutions per site per million years for the mutational rate at the root of the tree. The priors for rate roughly correspond to the median tip-to-root distance among lineages and partitions divided by $20 \mathrm{MY}$. Relatively large values for standard deviations $(>4 \times$ mean) were selected to accommodate rate variation among genes and codon positions. The prior for Brownian motion constant was 1.0 ( $\mathrm{SD}=1.0)$. Two nodes were subject to time constraints (derived from paleontological data: Jacobs and Downs, 1994; Jacobs et al., 1989, 1990; Jaeger et al., 1986): Mus/Rattus split (12 and 14 MYA), while corresponding upper and lower limits for Tatera/Gerbillus dichotomy were attributed to 7 and 9 MYA (Tong, 1989).

\section{Results}

\subsection{New sequences}

All sequences generated in the present study were deposited in EMBL (cytb: AJ973378-AJ973392), (12S: AY997819-AY997825, AY997828, AY997830, AY997832AY997835), (vWF: AM000037-AM000051).

The alignment of the cyt $b$ gene consists of 924 nucleotides for 17 taxa, $387(42 \%)$ of which are variable and $295(32 \%)$ parsimony-informative. The average ratio of $\mathrm{TS} / \mathrm{TV}$ is 1.56 , ranging from 0.98 to 5.87 . The complete alignment of the $12 \mathrm{~S}$ mitochondrial gene comprises 973 sites for 17 individuals. When the indels are removed from the matrix, 846 sites are included in the analyses. Of these $177(21 \%)$ are variable and $126(15 \%)$ parsimony-informative. The average ratio of $\mathrm{TS} / \mathrm{TV}$ is 2.67 , ranging from 1.47 to 6.5 . The alignment of the vWF sequences of 17 taxa (15 Cricetinae +2 Arvicolinae as outgroups) comprises 789 nucleotides of which 176 $(22 \%)$ are variable and $94(12 \%)$ parsimony informative.
The average ratio of $\mathrm{TS} / \mathrm{TV}$ is 3.12 , ranging from 1.59 to 7.5. The concatenated data matrix for the 17 taxa comprises 2548 nucleotides, $775(30 \%)$ variable and 537 (21\%) parsimony-informative.

\subsection{Saturation analysis}

Saturation analysis of the cyt $b$ data showed that transitions (TS) and transversions (TV) at positions 1 and 2 and TV at position 3 are moderately affected by homoplasy (TS 1: $S=0.69$; TV 1: $S=0.80$; TS 2: $S=0.64$; TV 2: $S=0.99$; TV 3: $S=0.53$ ). On the contrary, transitions at third position, are highly saturated ( $S=0.13$ ). Saturation analyses of the $12 \mathrm{~S}$ data sets were performed on four partitions: transitions and transversions were analyzed separately in loops and stems regions. There is no saturation for TV in stems $(S=0.99)$ and only moderate saturation for TS in stems $(S=0.75)$ and for both substitution types in loops (TS: $S=0.70$; TV: $S=0.67$ ). Saturation analysis of the vWF data set (17 taxa, 789 nucleotides) indicates that there is no saturation for TS and TV.

Therefore, all further analyses were conducted using all events of the three DNA regions, with the exception of TS at third codon position for cyt $b$.

\subsection{Phylogenic relationships between the different Cricetinae genera}

The ILD test showed no significant incongruence between the two mitochondrial genes $(p=0.25)$ as well as between these ones and $\mathrm{vWF}(p=0.17$ and 0.56 , respectively). Therefore, we concatenated these three genes to enhance the power of resolution. It should be mentioned that we also performed single gene analyses (data not shown) which produced largely similar phylogenetic trees validating the results of the concatenated sequence approach. Some differences inside the Cricetus-related clade (cytb/12S) have either low bootstrap support or seem to be random due to the low number of informative sites (position of M. auratus in $\mathrm{vWF}$ trees).

The combined analysis was performed with Arvicolinae (Clethrionomys glareolus) and Neotominae (Peromyscus leucopus) as outgroups. A consensus tree, constructed from the topologies retrieved by MP, ML, NJ, and Bayesian probabilities 5 (BAP) is presented in Fig. 2. The monophyly of the Cricetinae is strongly supported $(\mathrm{MP}=87$, $\mathrm{NJ}=99, \mathrm{ML}=98, \mathrm{BAP}=1.0)$. The most basal Cricetine genus is Phodopus ( $\mathrm{MP}=100, \mathrm{NJ}=100, \mathrm{ML}=100$, $\mathrm{BAP}=1.0$ ). Two main groups can be distinguished for the remaining Cricetinae taxa: a Mesocricetus group and a diversified lineage corresponding to the genera Cricetulus, Tscherskia, Cricetus, and Allocricetulus. The monophyly of both groups is well supported $(\mathrm{MP}=100, \mathrm{NJ}=100$, $\mathrm{ML}=100$, BAP $=1.0$ ).

Within these three main groups, different subclades are robustly supported: 


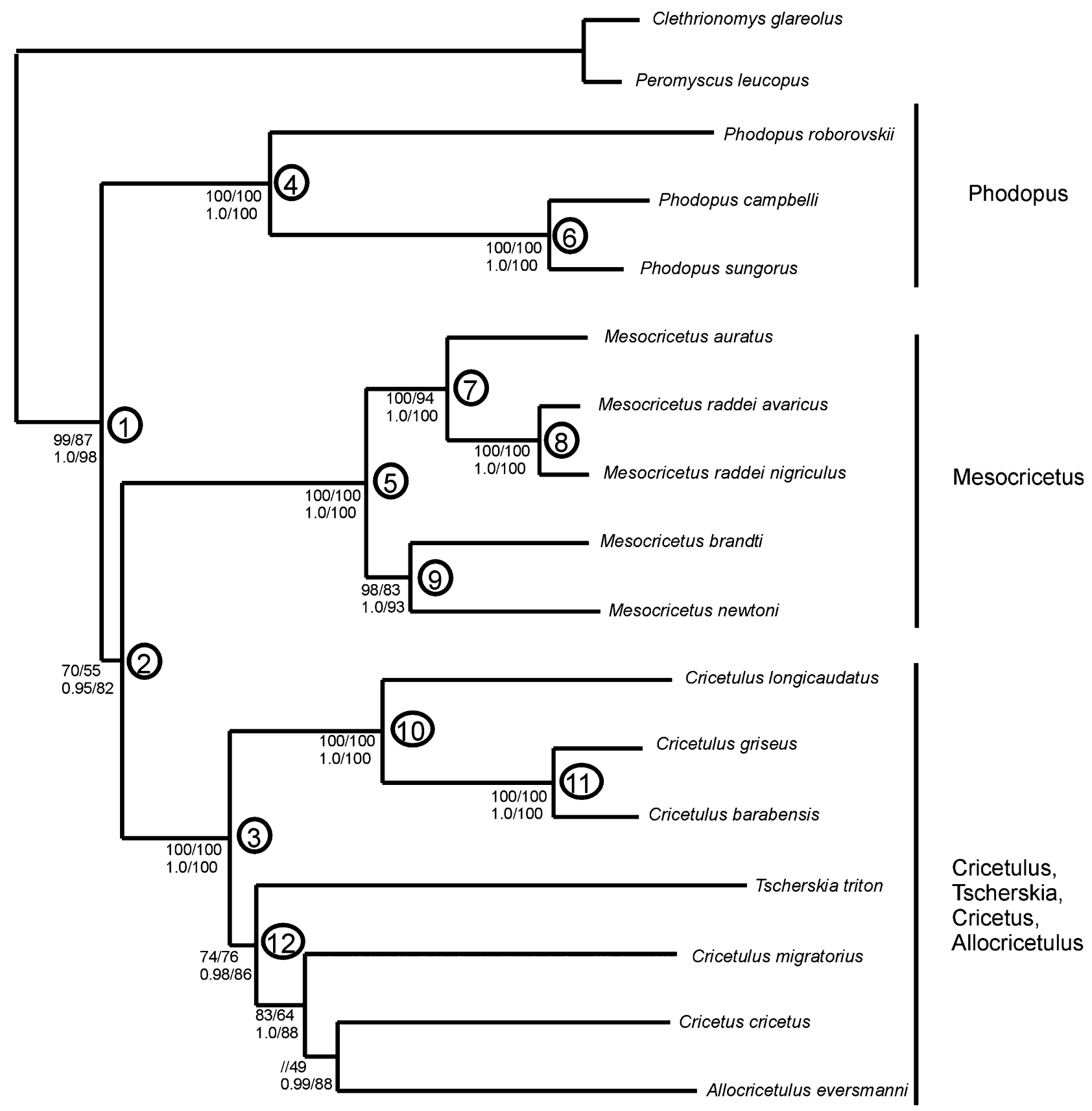

NJ/MP

Bayesian prob./ML

Fig. 2. Consensus tree obtained from the analysis of the concatenated genes for 15 taxa and 2559 positions, with the exclusion of transitions at third codon position for cyt $b$. Numbers inside opened circles correspond to the main nodes of the tree where divergence time estimates were calculated (see Table 3). Clethrionomus glareolus and Peromyscus leucopus are used to root the tree. For each node the different robustness indices are indicated as follows: $\frac{\text { NJ Bootstrap support/MP Bootstrap support }}{\text { Bayesian probabilities/ML Bootstrap support }}$.

- Phodopus campbelli and P. sungorus appear closely related $(\mathrm{MP}=100, \mathrm{NJ}=100, \mathrm{ML}=100, \mathrm{BAP}=1.0)$ and separated to $P$. roborovskii.

- Mesocricetus auratus is nested with M. raddei (subspecies avaricus, and nigriculus) in a same subclade $(\mathrm{MP}=100, \mathrm{NJ}=100, \mathrm{ML}=94, \mathrm{BAP}=1.0)$, which is well separated to another one corresponding to $M$. brandti and $M$. newtoni $(\mathrm{MP}=83, \mathrm{NJ}=98, \mathrm{ML}=93$, $\mathrm{BAP}=1.0)$.

- Cricetulus griseus and C. barabensis are strongly related $(\mathrm{MP}=100, \mathrm{NJ}=100, \mathrm{ML}=94, \mathrm{BAP}=1.0)$ and associated to $C$. longicaudatus $(\mathrm{MP}=100, \mathrm{NJ}=100$, 
$\mathrm{ML}=94, \mathrm{BAP}=1.0$ ) whereas they are well separated from a group corresponding to Tscherskia triton, Cricetulus migratorius, Cricetus cricetus, and Allocricetulus eversmanni.

A summary of the Kimura 2 parameter (K2P) sequence divergence values is presented in Table 2 for the three DNA regions, both within and between the studied genera. It indicates that the divergence between the genus Phodopus and the other Cricetinae genera is very high for the three DNA regions. An important level of genetic divergence is also observed between the genus Mesocricetus and Cricetulus, Tscherskia, Cricetus, and Allocricetulus. P. roborovski also appears highly divergent to the other studied Phodopus species suggesting an old separation between them. On the contrary, the genetic divergence is lower within Mesocricetus and Cricetulus.

\subsection{Divergence time}

The LRT rejected a clock for cyt $b$ and 12S $(p<0.001$ and $p<0.05$, respectively) but not for vWF ( $p=0.057$ ). However, the relative rate test indicated no significant rate heterogeneity between the three genes. Therefore, we consider the global clock strategy as potentially applicable in this case although its results should be interpreted with caution. To apply a global clock and to estimate times of divergence, we estimated the ML tree based on the combined data set with Cricetomys gambianus and Nesomys rufus as outgroup. The inferred maximum likelihood distances were used to estimate separation times.

The ML distance between Mus and Rattus that diverged $12 \mathrm{MY}$ ago is 0.233 . The one between Gerbillus and Tatera that diverged $8 \mathrm{MY}$ ago is 0.120 . These values give a rate of 0.015-0.016 (Mus/Rattus and Gerbillus/Tatera) ML distance per million years. When this rate is applied to the different dichotomies within the Cricetinae, the following molecular datings are obtained: 8.5-9 MY for the separation between the genus Phodopus and the other Cricetinae genera and 7.6-8.1 MY for the separation between Mesoc- ricetus and Cricetulus, Tscherskia, Cricetus, and Allocricetulus (see Table 3).

The relaxed clock method produced time estimates overlapping with those based on a general clock assumption although demonstrating a tendency for deeper earlier splits (see Table 3). Phodopus and Mesocricetus split at approximately 10.8-12.2 MY, while radiation within the Cricetusrelated group started 6.5-7.5 MY ago.

\section{Discussion}

\subsection{Phylogenetic structure and the evolution of higher taxa}

A gene phylogeny derived from concatenated genomic sequences revealed a clear partition of Palaearctic hamsters into three main evolutionary entities: 1. Phodopus group, 2. Mesocricetus group, 3. Cricetus-related group (Cricetus, Tscherskia, Allocricetulus, and Cricetulus). This grouping disagrees with previous systematic studies based on allozymes or morphological grounds (Carleton and Musser, 1984; Corbet, 1978; Fahlbusch, 1969; Flint, 1966; Kartavtsev et al., 1984b). However, the same three clades are largely delimited on the basis of chromosomal data (Kartavtseva, 2001; Radjabli, 1975).

Molecular clock results derived from global and relaxed clock assumptions are rather similar except for more ancient splits such as nodes 1 and 2, where both estimates deviate by 2-3 MY from each other. Moderate rate heterogeneity among genes (e.g., mt versus nuclear) and lineages may account for that. However, both estimates exceed fossil datings which makes a judgment of the validity of the calculations impossible. We prefer to use the entire span of divergence times for further discussions.

Splits between major phylogenetic clusters (node 1, node 2) are rooted in the upper Miocene around 7.6-12.2 MY ago. Noteworthy is the old age of the genus Phodopus (8.5-12.2 MY) because fossils were not reported before the Quarternary (Fahlbusch, 1969; Shaohua, 1984; Shaohua and Cai, 1991). Steppan et al. (2004) calculated a separation between Phodopus and Mesocricetus from four

Table 2

Degree of within and between genus divergence (K2P distances) for the cyt $b, 12 \mathrm{~S}$, and vWF genes

\begin{tabular}{|c|c|c|c|}
\hline Taxa compared & cyt $b$ & $12 \mathrm{~S}$ & vWF \\
\hline Phodopus/other Cricetinae (node 1) & 22.6 & 8.6 & 7.6 \\
\hline Mesocricetus/Cricetulus, Tscherskia, Cricetus, Allocricetulus (node 2) & 20.1 & 8.3 & 6.7 \\
\hline $\begin{array}{l}\text { C. longicaudatus, C. griseus, C. barabensis } / T \text {. triton, } \\
\text { C. migratorius, Cr. cricetus, A. eversmanni (node } 3 \text { ), }\end{array}$ & 20.0 & 7.6 & 3.8 \\
\hline P. roborovskii/P. campbelli, $P$. sungorus (node 4 ) & 18.4 & 5.2 & 4.6 \\
\hline M. brandti, M. newtoni/M. auratus, $M$. raddei (node 5) & 11.5 & 4.7 & 1.1 \\
\hline P. campbelli/P. sungorus (node 6) & 4.5 & 1 & 0.5 \\
\hline M. auratus/M. raddei (avaricus, nigriculus) (node 7) & 6.3 & 3.4 & 1.5 \\
\hline M. raddei avaricus/M. raddei nigriculus (node 8 ) & 2.3 & / & 0 \\
\hline M. brandti/M. newtoni (node 9) & 9.8 & 3.5 & 1 \\
\hline C. longicaudatus/C. griseus, C. barabensis (node 10) & 15.2 & 3 & 1.1 \\
\hline C. griseus/C. barabensis (node 11) & 4.3 & 0.9 & 1 \\
\hline T. triton/C. migratorius, Cr. cricetus, A. eversmanni (node 12) & 21.1 & 7.6 & 3.5 \\
\hline
\end{tabular}


Table 3

Time estimates for separation events within the subfamily Cricetinae (see Fig. 2, for node numbers), calculated from molecular data

\begin{tabular}{|c|c|c|c|c|c|c|}
\hline \multirow[t]{2}{*}{ Separation events } & \multicolumn{2}{|l|}{ Separation SC } & \multicolumn{2}{|c|}{ Separation SC } & \multicolumn{2}{|c|}{ Separation RC } \\
\hline & Gerbillus/Tatera & $\mathrm{SE}$ & Mus/Rattus & $\mathrm{SE}$ & & SD \\
\hline Mus/Rattus & 15 & 0.4 & 12 & / & 12.9 & 0.6 \\
\hline Gerbillus/Tatera & 8 & / & 7.5 & 0.4 & 7.9 & 0.6 \\
\hline Phodopus/other Cricetinae (node 1) & 9.0 & 0.2 & 8.5 & 0.2 & 12.2 & 2.0 \\
\hline $\begin{array}{l}\text { Mesocricetus/Cricetulus, Tscherskia, } \\
\text { Cricetus, Allocricetulus (node } 2 \text { ) }\end{array}$ & 8.1 & 0.2 & 7.6 & 0.2 & 10.8 & 1.9 \\
\hline $\begin{array}{l}\text { C. longicaudatus, C. griseus, C. barabensis } / T \text {. triton, } \\
\text { C. migratorius, Cr. cricetus, A. eversmanni (node } 3 \text { ) }\end{array}$ & 6.2 & 0.2 & 5.8 & 0.2 & 7.4 & 1.5 \\
\hline$P$. roborovskii/P. campbelli, $P$. sungorus (node 4 ) & 5.2 & 0.3 & 4.9 & 0.3 & 6.9 & 1.5 \\
\hline M. brandti, M. newtoni/M. auratus, $M$. raddei (node 5) & 2.7 & 0.2 & 2.5 & 0.2 & 2.7 & 0.8 \\
\hline$P$. campbelli/P. sungorus (node 6 ) & 0.9 & 0.1 & 0.8 & 0.1 & 1.0 & 0.5 \\
\hline M. auratus/M. raddei (avaricus, nigriculus) (node 7) & 1.5 & 0.1 & 1.3 & 0.1 & 1.2 & 0.5 \\
\hline M. raddei avaricus/M. raddei nigriculus (node 8 ) & 0.5 & 0.1 & 0.4 & 0.1 & 0.4 & 0.3 \\
\hline M. brandti/M. newtoni (node 9 ) & 1.8 & 0.1 & 1.7 & 0.1 & 1.7 & 0.6 \\
\hline C. longicaudatus/C. griseus, C. barabensis (node 10) & 3.1 & 0.1 & 2.9 & 0.1 & 3.1 & 0.9 \\
\hline C. griseus/C. barabensis (node 11) & 0.85 & 0.1 & 0.8 & 0.1 & 0.8 & 0.4 \\
\hline T. triton/C. migratorius, Cr. cricetus, A. eversmanni (node12) & 5.4 & 0.2 & 4.9 & 0.2 & 6.7 & 1.4 \\
\hline
\end{tabular}

The numbers in bold correspond to calibration points: 12 MY for the separation between Mus and Rattus (Jacobs and Downs, 1994; Jaeger et al., 1986) and 8 MY for the separation between Gerbillus and Tatera (Tong, 1989). SE = standard error values provided by the maximum-likelihood analysis of Puzzle 4.0. "SC" refers to a standard clock and "RC" to a relaxed clock.

nuclear genes at 13.5-14.1 MY ago. In contrast with fossils, our datings indicate that by the end of Miocene the two Phodopus branches had been already distinct and, hence the ghost time for the genus covers the entire Pliocene. A lack of records and misidentification of fossils may account for the discrepancy between fossil and genetic data (Schaub, 1930; Shaohua and Cai, 1991).

Uncertainties concerning species identity as well as phylogenetic relationships between fossil and extant hamsters impede a clear correlation between the rise of major hamster taxa and specific geographical or climatic events in the past. However, our results show a good congruence between the appearance of major phylogenetic lineages during the Late Miocene and the fossil based description of a large number of Cricetine species in Europe and Asia (McKenna and Bell, 1997) from the middle and late Miocene epoch. A major reason explaining such Cricetinae diversification would be the spread of steppe and open woodlands due to increasingly drier climatic conditions 8-10 MY ago. In particular during the late Miocene many parts of Europe and Asia were characterized by a drastic faunal turn over in favour of open land species due to ongoing global changes in vegetation (Cerling et al., 1997). The same time period was also characterized by tectonic changes such as a further uplift of the Tibetian plateau ( 10 MYA) providing physical barriers as well triggering climatic changes across Eurasia (Agustí et al., 1999; Fortelius et al., 2002). Most affected regions in Mongolia and China still harbour a significant number of hamster species (see also Figs. 1-3). It is reasonable to hypothesize that (Central?) Asian grasslands were the primary centre of diversification of major hamster taxa. However, some extinct genera which have been discussed as potential ancestors, in particular for the extant Cricetus-re-

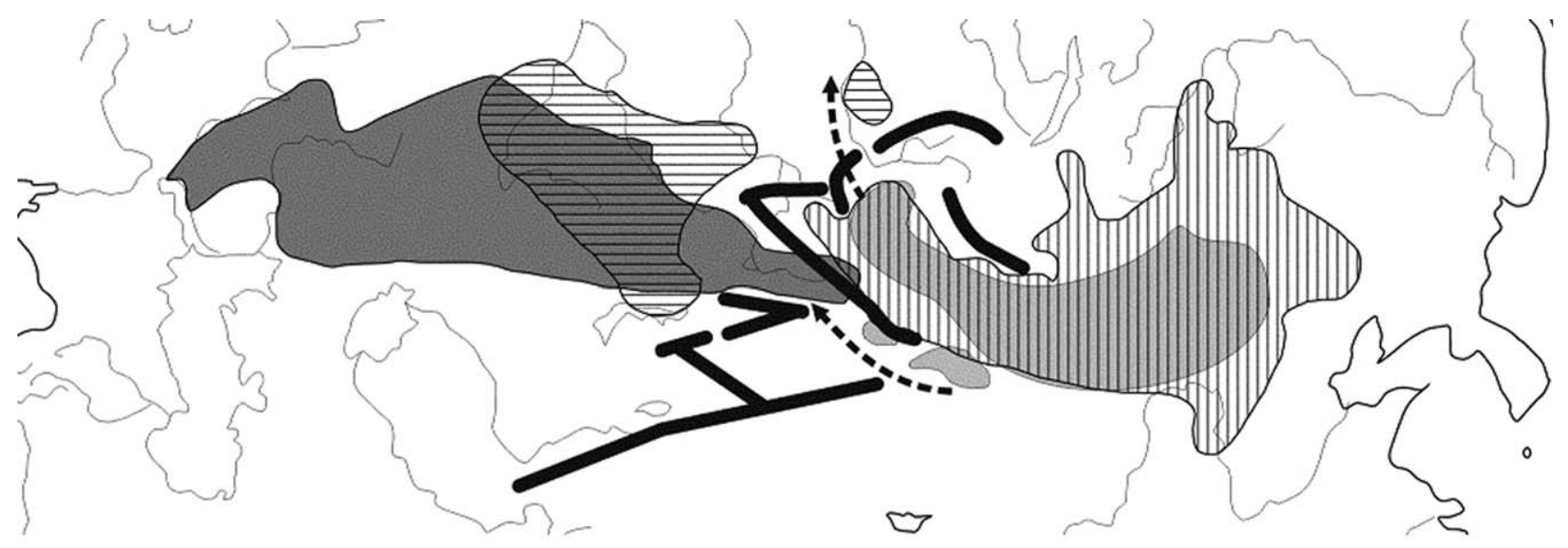

Fig. 3. Distribution areas of closely related sister species: $\square$ Allocricetulus eversmanni/ $\square$ A. curtatus, and $\boxminus$ Phodopus sungorus/而P. campbelli. Dark bars indicate mountain ranges of the Sajan-Altai. Arrows refer to potential migration routes during the Pleistocene. 
lated clade, e.g., Kowalskia were also reported from the late Miocene in Europe (McKenna and Bell, 1997). Shaohua (1984) speculates a phylogenetic link between Tscherskia triton and the extinct genus Kowalskia, which is known from both Europe and Asia since the late Miocene (Kowalski, 2001; Rummel, 1998). It is well possible that divergence within the Cricetus-related group took place within and outside the central Asian basin. Extant distributions give no clear signals as for instance Cricetus cricetus is mainly found in Europe and east of the Altai-Sajan whereas Tscherskia occurs in eastern China however, having recently become extinct in north-western Iran. The lack of Cricetus fossils in Mongolia and China as well as the fact that putative $C$. migratorius or $C$. migratorius-related fossils occurred in Europe since the older Pleistocene (Jánossy, 1986; Storch, 1975) and probably the late Pliocene (De Bruijn et al., 1970; Niethammer and Krapp, 1982) could imply an evolutionary centre of these species in Europe.

Unfortunately, the lack of clearly specified fossils does not allow pinpointing an ecological or geographical event leading to the divergence of the Phodopus group from the remaining clades. Clearer is the situation for Mesocricetus hamsters although no putative ancestral hamster taxon could be identified so far. Oldest fossils related to the Mesocricetus lineage come from the Aegean region such as $M$. primitivus from Chalkidike (L-Miocene/E-Pliocene) (Vasileiadou et al., 2003) and Rhodos (upper Pliocene; Bruijn et al., 1970) and central Turkey (E-Pliocene; Sevket et al., 1998). The distribution of Mesocricetus fossils dating to the Miocene/Pliocene boundary as well as the fact that all fossils found so far roughly coincide with the genus' recent geographical range strongly favour an evolutionary origin in the eastern Mediterranean (Storch, 2004). There is a number of evidence supporting climatic change and the formation of steppe-like landscape following the raise of the Aegean and Anatolian land mass during the middle and late Miocene (Lüttig and Steffens, 1975) (Fig. 4).

The spread of deserts across Asia during the Pliocene has likely facilitated a further diversification within major hamster clades mainly triggering the radiation of Cricetus-related hamsters. This clade harbours most of the extant hamster species which are distributed from western Europe to eastern Asia indicating a relatively wide ecological potential compared to the other main hamster lineages. Congruent with such a scenario is the appearence of hamsters of the Cricetulus-type in the Russian steppe since the middle Pliocene (Gromova, 1962).

\subsection{Late tertiary and quaternary expansion led to longitudinal range splits and speciation}

Some closely related hamster species have allopatric ranges in east-west orientation; Allocricetulus eversmannil A. curtatus, Phodopus campbelli/P. sungorus, Cricetulus barabensis group (Fig. 3). Such a longitudinal zonation is typical for the eastern part of Mongolia and China and adjacent Siberia and Kazakhstan where the Sajan-Altai mountains function as efficient gene flow barriers. This distribution of subdivided populations is comparable to the phylogeographic pattern of steppe plants (Franzke et al., 2004). A belt of steppe has repeatedly functioned as an expansion corridor from the central Asian plateau to the west. At times of favourable climatic conditions hamsters were able to pass (river valleys, e.g., Irtysch, Yennisej) or bypass the mountain area crossing Dsungaria (see Fig. 3). Franzke et al. (2004) estimated a time of 0.5-1.1 MY for

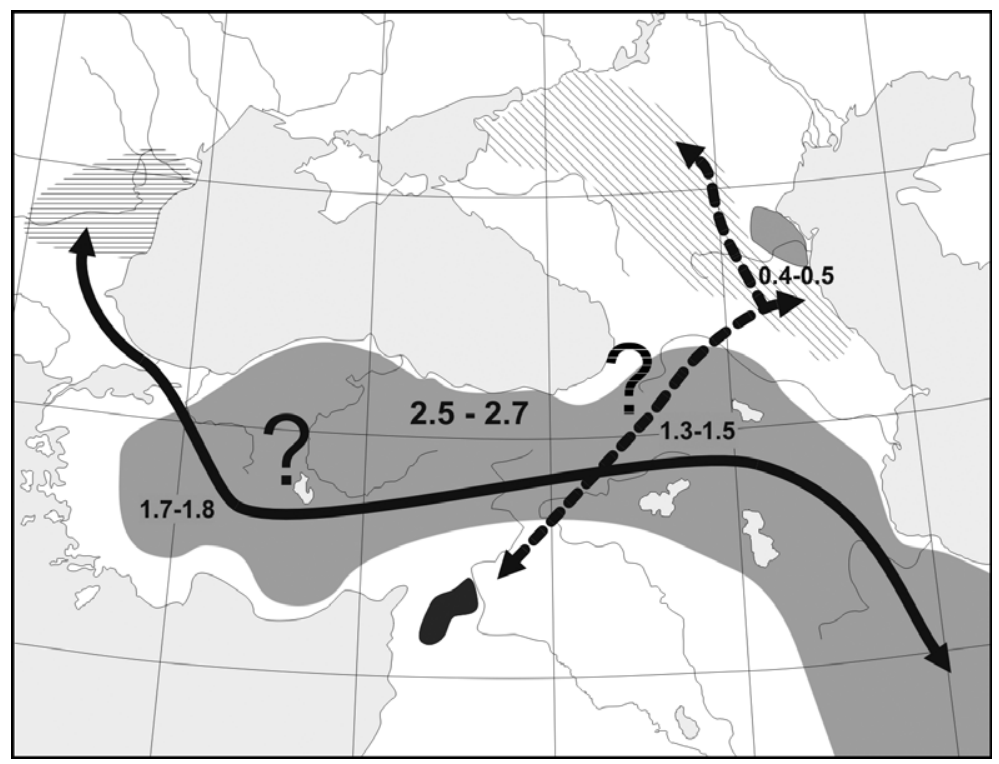

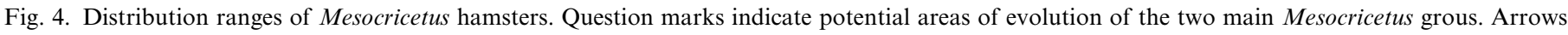

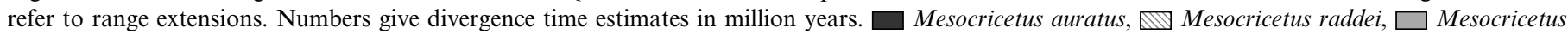
brandti, and $\equiv$ Mesocricetus newtoni. 
the divergence of population groups in the steppe plant Clausia aprica covering the discussed geographical area. A divergence time of 0.8-1.0 MY between Phodopus campbelli and $P$. sungorus falls exactly in this range implying a strong correlation between quarternary expansion of steppe and migration of Asian hamster populations. Western range extensions during cooler periods of the Quarternary followed by a subsequent disintegration of populations due to deteriorating ecological conditions (cooling or warming maxima) were found to be a key mechanism for genetic subdivision in common hamster populations (Neumann et al., 2005 ) and most likely accounts for longitudinal speciation. Unfortunately, there are hardly genetic data for other steppe adapted mammals in the Sajan-Altai region to investigate the importance of such a speciation process. The spatial distributions of steppe lemmings Eolagurus luteus-E. przewalskii and feather-tailed jerboas Stylodipus andrewsi $-S$. telum/S. sungorus (see Panteleyev, 1998) are similar to that of the above mentioned central Asian hamsters and could be the result of a westward expansion.

\subsection{Genetic evaluation of the species' systematic positions}

\subsubsection{Genus: Phodopus}

The genus harbours small sized hamsters with peculiar adaptations to extreme temperatures such as hairy feet and special thermoregulation (Newkirk et al., 1998; Ross, 1994, 1995, 1998). Furthermore, Phodopus species are the only known hamsters showing high social tolerance and even biparental behaviour (Wynne-Edwards and Lisk, 1987).

Controversial opinions exist about the validity of Phodopus campbelli which is sometimes considered to represent only a subspecies of $P$. sungorus (Flint, 1966; Honacki et al., 1982). Our phylogenetic analyses (see Table 2) indicate that the two dwarf hamsters are very closely related, e.g., for cyt $b$, they are only separated by $4.5 \%$ of genetic divergence. The cyt $b$ value is inside the intraspecific range and well below the mean K2P distance expected for sister species in rodents (Bradley and Baker, 2001). Both species have probably split $0.8-1.0 \mathrm{MY}$ ago during the Pleistocene. Our dating correlates with the divergence time proposed by Lougheed et al., 2003; cited in Wynne-Edwards (2003). The time estimate falls in a period of relative climatic instability with a short stadial (0.9-0.8 MY) interrupting two warming periods. Late Pleistocene remains of Phodopus hamster were reported from different places in Europe (Rathgeber and Ziegler, 2003; Schaub, 1930; but questioned in Gromov and Baranova (1981) and Asia (Shaohua, 1984) implying a temporarily wider distribution. It is likely that $P$. sungorus populations are relicts of an old westward expansion during the Biharian stage of the Pleistocene presuming that Phodopus hamsters originated close to its recent main distribution area. Notable is the distinguished position of $P$. roborovskii which shows a higher degree of divergence to $P$. campbelli/sungorus than found between some other acknowledged hamster genera. Cyt $b$ distances measure $19.2 \pm 1.6 \% / 18.0 \pm 1.6 \%$ what is above the average expected for intrageneric differentiation in small mammals (Bradley and Baker, 2001). Profound genetic differences between $P$. roborovskii and $P$. campbelli/sungorus go in line with a number of morphological characters dividing the species (Argyropulo, 1933; Ross, 1994; Vorontsov, 1960). P. roborovskii is not only the smallest of all hamsters but is also the only one which is adapted to extreme arid desert conditions living preferentially along sand dunes. Schmid et al. (1986) considered the karyotype of $P$. roborovskii to be more primitive than that of $P$. campbelli and $P$. sungorus. For those reasons we propose to place $P$. campbelli and $P$. sungorus in the genus Cricetiscus following Thomas (1917).

\subsubsection{Genus: Mesocricetus}

Four species have been accepted so far; $M$. raddei, M. newtoni, M. brandti, and M. auratus (Wilson and Reeder, 1993). Sequence data confirm the validity of those species but revealed much greater genetic distances as expected from morphological data (Hamar and Schutowa, 1966; Yigit et al., 2000). M. raddei nigriculus appears genetically very closely related to $M$. raddei avaricus. Morphological differences between the two "subspecies" are therefore likely the result of ecological adaptations. The smaller $M$. r. nigriculus occurs in the ciscaucasian lowlands whereas $M$. $r$. avaricus is an element of the mountainous steppe regions in central Dagestan. Mesocricetus hamsters show mainly a vertical zonation of species ranges which are divided by mountain chains; the Caucasus and the Taurus. A separation of Mesocricetus hamsters into a cis- and a transcaucasian group as proposed by Hamar and Schutowa (1966) could no be confirmed. Reason therefore is the close association of the transcaucasian $M$. auratus with the ciscaucasian $M$. raddei. Current distribution areas of both species are highly isolated from each other (M. raddei-Caucasus, M. auratus-Aleppinian plateau) and account for range displacement during the Pleistocene (1.3-1.5 MY). Mesocricetus hamsters of the auratus/ brandti-type appeared in south-west Asia, the Aegaeis and the Caucasus region throughout the Pleistocene and since the lower Palaeolithicum in Transcaucasia (Güleç et al., 1999; Storch, 1975; Tchernov, 1975; Vereshchagin, 1959). Molecular clock estimates indicate a separation between the $M$. brandti/M. newtoni and $M$. raddei/M. auratus group during the upper Pliocene. It is well possible that the spread of dry steppe habitats and tectonic changes supported an early split into a western (west/central Anatolia) and an eastern (Caucasian) Mesocricetus group. Vereshchagin (1959) suggested a penetration of the Caucasus by Mesocricetus hamsters as early as in the upper Pliocene. Disintegration of the eastern Mesocricetus group (M. auratus/M. raddei) may have occurred during the lower/mid Pleistocene a time with significant range extensions in Mesocricetus hamsters (Vereshchagin, 1959). Unfortunately, there are no reliable fossil data to time the arrival of $M$. auratus in its contemporary range but its most southerly boundary was reached about 40 KY ago (Tchernov, 1975). 
The separation of $M$. brandti and $M$. newtoni occurred probably during an early stage of the Pleistocene. Our time estimate $(\sim 1.7-1.8 \mathrm{MY})$ slightly predates middle Pleistocene fossil records (M. cf. newtoni) from Turkish Thrace (Santel and von Königswald, 1998). M. newtoni probably reached its contemporary range during the Holsteinium (Kowalski, 2001).

Shifting altitudes and vegetation changes in the Caucasus, a further uplift of the Taurus as well as multiple transgressions of the Caspian, Black and Mediterranean sea are very likely responsible for the relatively rapid radiation of Mesocricetus species during the Pleistocene. Noteworthy is that competition between Cricetus and Mesocricetus (Tchernov, 1975) could be an important factor which restricts the range of Mesocricetus in the north and west.

\subsubsection{Genus: Cricetulus}

Cricetulus is with eight (Panteleyev, 1998) or six species (Duff and Lawson, 2004) the largest hamster genus and provides most identification difficulties. Four species groups are easily recognized on morphological features including monotypic migratorius and longicaudatus groups, barabensis group with four chromosomal forms (barabensis, griseus, pseudogriseus, and sokolovi) the ranks of which are still disputed, and yet poorly known kamensis group treated as a subgenus Urocricetus. Our sample contained only four species $C$. barabensis, $C$. griseus, $C$. longicaudatus, and $C$. migratorius. The species identity of $C$. griseus is largely based on karyological grounds (Matthey, 1960) but its relevance is questioned (Král et al., 1984). Some authors consider $C$. griseus only as a subspecies of $C$. barabensis (Wilson and Reeder, 1993). The genetic distance obtained in the present study between $C$. griseus and $C$. barabensis falls in this last range (Table 2) and is similar to what is observed between Phodopus campbelli and P. sungorus. Differentiation of the barabensis/griseus group probably occurred in the late to middle Pleistocenic period due to the expansion/contraction of areas caused by changes in humidity levels. C. longicaudatus forms a stable, wellsupported association with the two representatives of the barabensis group. This outcome is not unexpected due to a high level of morphologic similarity between the two groups which are sometimes lumped into a single one (Pavlinov and Rossolimo, 1987). The most striking result is the lack of monophyly of the genus Cricetulus. The widespread Cricetulus migratorius stands outside the actual Cricetulus group and is more affiliated with Cricetus and Allocricetulus. As a consequence we propose to place the species in a new monotypic genus. At this point it should be mentioned that a preliminary study on the $12 \mathrm{~S}$ of $C$. (Urocricetus) lama (Lebedev et al., 2003) identified the species as a potential sister genus of Phodopus or a representative of very basal hamster taxon. Summarizing all genetic evidence one has to conclude that the genus Cricetulus represents just a "dustbin" of small-sized hamsters with advanced dental morphology.

\subsubsection{Genus: Tscherskia}

Tscherskia triton does clearly not belong to the genus Cricetulus. It represents a separate lineage within the Cricetus/Cricetulus group which might be closer to Cricetus and Allocricetulus. The taxon evolved at the end of the Miocene/early Pliocene. Shaohua (1984) postulates T. triton as a descendant of Cricetinus (Tscherskia) varians which is according to him very likely related to Kowalskia. The relationship of Tscherskia with Cansumys remains to be established. The latter genus was for long treated as a synonym of Tscherskia. However, no genetic data on Cansumys is available thus far.

\subsubsection{Genus: Cricetus}

The common hamster Cricetus cricetus is the only hamster genus of the Cricetus-related clade, which lives exclusively west of the Sajan-Altai. Typical Cricetus hamsters were found from the beginning of the Pleistocene (Hir, 1997; Niethammer and Krapp, 1982) but only Cricetus cricetus survived areal shifts and local extinction during glacial oscillations. Mein and Freudenthal (1971) questioned the generic identity of Pliocenic and Quarternary Cricetus species. DNA data place the origin of the genus Cricetus in the upper Pliocene what recommends a re-evaluation of these records. In fact, Topachevskiy and Skorik (1992) place Cricetus kormosi and some other Cricetus forms from the late Miocene to a new genus Pseudocricetus. Freudenthal et al. (1998) describe European C. kormosi or C. $c f$. kormosi from the late Miocene and Pliocene as Apocricetus alberti. Both views are concordant with our molecular findings.

\subsubsection{Genus: Allocricetulus}

The genus harbours two closely related species $A$. eversmanni and A. curtatus. DNA sequence analysis of $A$. eversmanni confirms the validity of an own genus and places the species in close neighbourhood to Cricetus. Published fossil records date exclusively from the Pleistocene (Flint, 1966). Our clock estimates place the origin of the genus already in the Pliocene.

\section{Conclusions}

The presented DNA based phylogeny of the subfamily Cricetinae provides significant new insights in the evolutionary history and systematics of old world hamsters. Our study evidenced that the Cricetinae are separated in three main genetic lineages which diversified in two different periods, firstly during the middle/end of Miocene, and secondly during the latest Miocene/Pliocene. Withingenus phylogenies root mainly in the Pliocene/Pleistocene boundary. The diversification is probably the result of important global climate changes which appeared during these periods all over the Palearctic region. Such large scale climatic events include above all the formation of extensive grass lands during dry parts of the late Tertiary as well as the further uprise of Asian mountain chains. During the 
Pleistocene, longitudinal range expansions led to the evolution of closely related sister species west of their native central Asian range. Problematic for the systematics point of view are the varying levels of sequence divergence within and between genera. They hardly justify the maintenance of a single genus Phodopus or vice versa the establishment of different genera within the Cricetus-related group.

However, our genetic data can only provide a framework for further investigations as not all currently acknowledged species could be included. In particular a comprehensive taxonomic revision of the Cricetulus hamsters is desirable. The relatively poor fit of genetic and fossil data requires an urgent reevaluation of fossil identifications to verify molecular clock estimates. However, the presented data will now allow examining the ecological and climatic circumstances which formed the observed phylogenetic pattern not only on a global but also on a regional scale, e.g., the importance of the Sajan-Altai barrier for the population exchange between the central Asian plateau and the adjacent western lowlands. Hamsters can thereby provide an important reference group for other Eurasian steppe taxa. A future study should include the missing species mentioned to confirm our different hypotheses and to provide a definitive idea about the phylogeny of this still underrepresented Muroid subfamily.

\section{Acknowledgments}

We thank G. Becke and B. Gebhardt for technical assistance. We are grateful to all who contributed samples e.g., S. Hauer, M-J Song. Special thanks go to J.G. Storch of the Senckenberg Museum for valuable discussions. G. Mundt is acknowledged for drawing the maps. We much appreciate the helpful comments of two anonymous reviewers. This research was partially funded by grants of the program "Scientific basics of Biodiversity Conservation in Russia."

\section{References}

Agustí, J., Cabrera, L., Garcés, M., Llenas, M., 1999. Mammal turnover and global climate change in the Late Miocene terrestrial record of the Vallès-Penedès Basin (NE Spain). In: Agustí, J., Rook, L., Andrews, P. (Eds.), The Evolution of Neogen Terrestrial Ecosystems in Europe. Cambridge University Press, Cambridge, MA.

Argyropulo, A.I., 1933. Die Gattungen und Arten der Hamster (Cricetinae Murray, 1866) der Palaearctic. Zeitschrift für Säugetierkunde 20, 129-149.

Argyropulo, A.I., 1938. On the fauna of Tertiary Cricetinae of the USSR. C.R. Acad. Sci. USSR, Moskau 20, 226-233.

Bradley, R.D, Baker, R.J., 2001. A test of the genetic species concept: cytochrome- $b$ sequences and mammals. J. Mammal. 82, 960-973.

Bruijn, H.D.E., Dawson, M.R., Mein, P., 1970. Upper Pliocene rodentia, Lagomorpha and Insectivora (Mammalia) from the Isla of Rhodes (Greece) I-III. Proc. Koninkl. Nederl. Akad. Wet B 73, 314-338.

Carleton, M.D., Musser, G.G., 1984. Muroid rodents. In: Anderson, S., Jones, J.K., Jr.Jr. (Eds.), Orders and Families of Recent Mammals of the World. Wiley, New York.

Cerling, T.E., Harris, J.M., MacFadden, B.J., Leakey, M.G., Quade, J., Eisenmann, V., Ehleringer, J.R., 1997. Global vegetation change through the Miocene/Pliocene boundary. Nature 389, 153-158.
Corbet, G.B., 1978. The Mammals of the Palaearctic Region. A Taxonomic Review. Ithaca, London.

Duff, A., Lawson, A., 2004. Mammals of the World-A Checklist. A\&C Black, London.

Fahlbusch, V., 1969. Pliozäne und pleistozäne Cricetinae (Rodentia, Mammalia) aus Polen. Acta Zool. Cracovienisa 14, 99-137.

Farris, J.S., 1985. Distance data revisited. Cladistics 1, 67-85.

Felsenstein, J., 1981. Evolutionary trees from DNA sequences: a maximum likelihood approach. J. Mol. Evolut. 17, 368-376.

Fitch, W.M., 1971. Towards defining the course of evolution: minimum change for a specific tree topology. Systematics Zool. 20, 406-416.

Flint, W.E., 1966. Die Zwerghamster der Paläarktischen Fauna. Ziemsen Verlag, Lutherstadt-Wittenberg.

Fortelius, M., Eronen, J., Jernvall, J., Liu, L., Pushkina, D., Rinne, J., Tesakow, A., Vislobokova, I., Zhang, Z., Zhou, L., 2002. Fossil mammals resolve regional patterns of Eurasian climate change over 20 million years. Evolut. Ecol. Res. 4, 1005-1016.

Franzke, A., Hurka, H., Janssen, D., Neuffer, B., Friesen, N., Markov, M., Mummenhoff, K., 2004. Molecular signals for Late tertiary/early quarternary range splits of an Eurasian steppe plant: Clausia aprica (Brassicaceae). Mol. Ecol. 13, 2789-2795.

Freudenthal, M., Mein, P., Suárez, M., 1998. Revision of Late Miocene and Pliocene Cricetinae (Rodentia, Mammalia) from Spain and France. Treballs Museu Geol. Barcelona 7, 11-93.

Gamperl, R., Vistorin, G., Rosenkranz, W., 1978. Comparison of chromosome banding patterns in five members of Cricetinae with comments on possible relationships. Caryologia 3, 343-353.

Gromov, I.M., Baranova, G.I., 1981. Catalogue of Mammals of the USSR. Nauka, Leningrad.

Gromova, V.I., 1962. Fundamentals of Paleontology. vol XIII: Mammals, Moscow.

Güleç, E., Howell, C., White, T.D., 1999. Dursunlu-A new lower Pleistocene faunal and artifact-bearing locality in southern Anatolia. In: Ullrich, H. (Ed.), Hominid Evolution: Lifestyles and Survival Strategies. Edition Archea, Berlin, pp. 349-364.

Hamar, M., Schutowa, M., 1966. Neue Daten über die geographische Veränderlichkeit und die Entwicklung der Gattung Mesocricetus Nehring, 1898 (Glires, Mammalia). Zeitschrift Säugetierkunde 31, 237-251.

Hassanin, A., Lecointre, G., Tillier, S., 1998. The "evolutionary signal" of homoplasy in protein-coding gene sequences and its consequences for a priori weighting in phylogeny. C.R. Acad. Sci. Paris 321, 611-620.

Hir, J., 1997. A short scetch of the evolution and stratigraphy of the PlioPleistocene cricetids (Rodentia, Mammalia) in Hungary. Folia Historico Naturalia Musei Matraensis 22, 43-49.

Honacki, J.H., Kinman, K.E., Koepfl, J.W., 1982. Mammal Species of the World: A Taxonomic and Geographic Reference. Allen Press, The Association of Systematics Colections, Lawrence, Kansas.

Huchon, D., Catzeflis, F., Douzery, E.J.P., 1999. Molecular evolution of the nuclear Willebrand factor gene in mammals and the phylogeny of rodents. Mol. Biol. Evolut. 16, 577-589.

Huelsenbeck, J.P., Ronquist, F., 2001. MrBayes: A Program for the Bayesian Inference of Phylogeny. Rochester, New York.

Huelsenbeck, J.P., Ronquist, F., Nielsen, R., Bollback, J.P., 2001. Bayesian inference of phylogeny and its impact on evolutionary biology. Science 294, 2310-2314.

Jacobs, L.L., Downs, W.R., 1994. The evolution of murine rodents in Asia. In: Tomida, Y., Li, C., Setoguchi, T. (Eds.), Rodent and lagomorph families of Asian origins and diversification. National Science Museum Monographs, Tokyo, pp. 149-156.

Jacobs, L.L., Winkler, D.A., Murry, P.A., 1989. Modern mammal origins: evolutionary grades in the Early Cretaceous of North America. Proc. Natl. Acad. Sci. USA 86, 4992-4995.

Jacobs, L.L., Flynn, L.J., Downs, W.R., Barry, J.C., 1990. Quo vadis, Antemus? The Siwalik muroid record. In: Linday, E.H., Fahlbusch, V., Mein, P. (Eds.), European Neogene Mammal Chronology. Plenum Press, New York, pp. 573-586. 
Jaeger, J.-J., Tong, H., Buffetaut, E., 1986. The age of Mus-Rattus divergence: paleontological data compared with the molecular clock. C.R. Acad. Sci., Paris, ser. 2 302, 917-922.

Jánossy, D., 1986. Pleistocene Vertebrate Faunas of Hungary. Developments in Palaeontology and Stratigraphy, vol. 8. Elsevier, Amsterdam.

Kartavtsev, Y.F., Kartavtseva, I.V., Vorontsov, N.N., 1984a. Population genetics and genogeography of wild mammals IV. Levels of heterozygosity in five species of Palearctic hamsters (Mammalia, Cricetinae). Genetika 20, 954-960.

Kartavtsev, Y.F., Kartavtseva, I.V., Vorontsov, N.N., 1984b. Population genetics and genogeography of wild mammals V. Genetic distances between representatives of different genera of Palearctic hamsters (Rodentia, Cricetini). Genetika 20, 961-966.

Kartavtseva, I.V., 2001. Comparative cytogenetics and origin of Palearctic hamsters (Rodentia, Cricetidae, Cricetini). Abstr. Intern. Conf. Evolution, Genetics, Ecology, \& Biodiversity. Vladivostok, 58.

Kowalski, K., 2001. Pleistocen rodents of Europe. Folia Quarternaria, 72.

Král, B., Radjabli, S.I., Grafodatskij, A.S., Orlov, V.N., 1984. Comparison of karyotypes, G-bands and NORS in three Cricetulus spp. (Cricetidae, Rodentia). Folia Zool. 33, 85-96.

Kuznetsov, G.V., Kulikov, E.E., Petrov, N.B., Ivanova, N.V., Lomov, A.A., Kholodova, M.V., Poltaraus, A.B., 2001. The "Linh Duong" Pseudonovibos spiralis (Mammalia, Artiodactyla) is a new buffalo. Naturwissenschaften 88, 123-125.

Lebedev, V.S., Ivanova, N.V., Pavlova, N.K., Poltoraus, A.B., 2003. Molecular phylogeny of the Palearctic hamsters. In: Averianov, A., Abramson, N. (Eds.), Proceedings of the International Conference Devoted to the 90th Anniversary of Prof. I.M. Gromov on Systematics, Phylogeny and Paleontology of Small Mammals. Saint Petersburg. pp. 114-118.

Lüttig, G., Steffens, P., 1975. Paleogeographic atlas of Turkey from the Oligocene to the Pleistocene. Bundesanstalt für Geowissenschaften, Hannover.

Matthey, R., 1960. Chromosomes, héterochromosomes et cytologie comparée des Cricetinae paléarctiques (Rodentia). Caryologia 13, 199-223.

Matthey, R., 1961. Cytologie comparée des Cricetinae paléarctiques et américains. Rev. Suisse Zool. 68, 41-61.

McKenna, M.C., Bell, S.K., 1997. Classification of Mammals above the Species Level. Columbia University Press, New York.

Mein, P., Freudenthal, M., 1971. Une nouvelle classification des Cricetidae (Mammalia, Rodentia) du Tertiaire de l' Europe. Scr. Geol. 2, 1-37.

Michaux, J., Reyes, A., Catzeflis, F., 2001. Evolutionary history of most speciose mammals: molecular phylogeny of muroid rodents. Mol. Biol. Evolut. 18, 2017-2031.

Neumann, K., Michaux, J.R., Maak, S., Jansman, H.A.H., Kayser, A., Mundt, G., Gattermann, R., 2005. Genetic spatial structure of European common hamsters - a result of repeated range expansion and demographic bottlenecks. Mol. Ecol. 14, 1473-1483.

Newkirk, K.D., Cheung, B.L.W., Scribner, S.J., Wynne-Edwards, K.E., 1998. Earlier thermoregulation and consequences for pup growth in the Siberian versus Djungarian dwarf hamster (Phodopus). Physiol. Behav. 63, 435-443.

Niethammer, J., Krapp, F., 1982. Handbuch der Säugetiere Europas, Bd2/ I, Rodentia II. Wiesbaden.

Panteleyev, P.A., 1998. The Rodents of the Palaearctic. AN Severtzov IEE of RAS, Moscow.

Pavlinov, I.Y., Rossolimo, O.L., 1987. Systematics of Mammals of the USSR. Moscow State University, Moscow.

Philippe, H., 1993. MUST, a computer package for Management Utilities for Sequences and Trees. Nucleic Acids Res. 21, 5264-5272.

Philippe, H., Douzery, E., 1994. The pitfalls of molecular phylogeny based on four species as illustrated by the Cetacea/Artiodactyla relationships. J. Mammal. Evolut. 2, 133-152.

Posada, D., Crandall, K.A., 1998. Modeltest: testing the model of DNA substitution. Bioinformatics 14, 817-818.

Radjabli, S.I., 1975. Karyotipic differentiation in Palearctic hamsters (Rodentia, Cricetinae). Dokl. Akad. Nauk. USSR 225, 697-700 (in Russian).
Rathgeber, T., Ziegler, R., 2003. Die Säugetiere im Quartär von BadenWürttemberg. In: Braun, M., Dieterlen, F. (Eds.), Die Säugetiere Baden-Württembergs Bd.1. Eugen Ulmer GmbH \& Co, Stuttgart, pp. 97-139.

Robinson, M., Gouy, M., Gautier, C., Mouchiroud, D., 1998. Sensitivity of the relative-rate test to taxonomic sampling. Mol. Biol. Evolut. 15, 1091-1098.

Ross, P.D., 1994. Mammalian species: Phodopus roborovskii. Am. Soc. Mammal. 459, 1-4

Ross, P.D., 1995. Mammalian species: Phodopus campbelli. Am. Soc. Mammal. 503, 1-7.

Ross, P.D., 1998. Mammalian species: Phodopus sungorus. Am. Soc. Mammal. 595, 1-9.

Rummel, M., 1998. Die Cricetiden aus dem Mittel- und Obermiozän der Türkei. Documenta Naturae, 123.

Saitou, N., Nei, M., 1987. The neighbor-joining method: a new method for reconstructing phylogenetic trees. Mol. Biol. Evolut. 4, 206-425.

Santel, W., von Königswald, W., 1998. Preliminary report on the middle Pleistocene small mammal fauna from Yarimburgaz cave in Turkish Thrace. Eiszeitalter und Gegenwart 48, 162-169.

Schaub, S., 1930. Quartäre und jungtertiäre Hamster. Abhandlungen der Schweizerischen Palaeontologischen Gesellschaft IL. Birkhäuser \& Cie, Basel.

Schmid, M., Haaf, T., Weis, H., Schempp, W., 1986. Chromosomal homologies in hamster species of the genus Phodopus (Rodentia, Cricetinae). Cytogenet. Cell Genet. 43, 168-173.

Sevket, S., Bouvrain, G., Geraads, D., 1998. Pliocene vertebrate locality of Çalta, Ankara, Turkey. 12. Paleoecology, biogeography and biochronology. Geodiversitas 20, 497-510.

Shaohua, Z., 1984. A revision of the fossil cricetines (Rodentia, Mammalia) from Zhoukoudian, the Peking Man site. Vertebrata PalAsiatica 22, 179-197.

Shaohua, Z., Cai, B., 1991. Fossil micromammals from the Donggou section of Dongyaozitou Yuxian county, Hebei province. Contributions to INQUA XIII. 100-131.

Steppan, S.J., Adkins, R.M., Anderson, J., 2004. Phylogeny and divergence-date estimates of rapid radiations in muroid rodents based on multiple nuclear genes. Systematic Biol. 53, 533-553.

Storch, G., 1975. Eine mittelpleistozäne Nagerfauna von der Insel Chios. Ägäis. Senckenbergiana Biol. 56, 165-189.

Storch, G., 2004. Late Pleistocene rodent dispersal in the Balkans. In: Griffith, H.I. et al. (Eds.), Balkan Biodiversity. Kluwer Academic Publishers, Dordrecht, pp. 135-145.

Swofford, D.L., 1998. PAUP*. Phylogenetic Analysis Using Parsimony (* and other methods). Version 4. Sinauer Associates, Sunderland, MA.

Tchernov, E., 1975. Rodent fauna and environmental change in the Pleistocene of Israel. In: Prakash, I., Ghosh, P.K. (Eds.), Rodents in Desert Environments. Hague, pp. 331-362.

Thomas, O., 1917. On the small hamsters that have been referred to Cricetulus phaeus und campbelli. Ann. Mag. Nat. History 19 (8), 456-457.

Thorne, J.L., Kishino, H., 2002. Divergence time and evolutionary rate estimation with multilocus data. Systematic Biol. 51, 689-702.

Thorne, J.L., Kishino, H., Painter, I.S., 1998. Estimating the rate of evolution of the rate of molecular evolution. Mol. Biol. Evolut. 15, $1647-1657$.

Tong, H., 1989. Origine et évolution des Gerbillidae (Mammalia, Rodentia) en Afrique du Nord. Mémoires Soc Géol. France 155, 120.

Topachevskiy, V.A., Skorik, A.F., 1992. Neogene and Pleistocene primitive Cricetidae of the south of eastern Europe. Naukova dumka, Kiev, 242 pp. (in Russian).

Vasileiadou, K.V., Syrides, G.E., Koufos, G.D., 2003. Silata, A new Locality with Micromammals from the Miocene/Pliocene bound of the Chalkidiki Peninsula, Macedonia, Greece. Deinsea 10, 549-562.

Vereshchagin, N.K., 1959. The Mammals of the Caucasus. A History of the Evolution of the Fauna. Moskau, Leningrad (English Translation, Jerusalem, 1969). 
Vorontsov, N.N., 1960. Species of Palaearctic hamsters (Cricetinae, Rodentia) in statu nascendi. Doklady Biol. Sci. Sections 132, 491-493.

Vorontsov, N.N., 1982. Primitive Cricetids (Cricetidae) of the World Fauna. vol. 1. Morphology and Ecology. In: Fauna SSSR, N125, Mlekopitayushchiye, vol. 111, Part 6. p. 451 (in Russian).

Wilson, D.E., Reeder, D.M., 1993. Mammal Species of the World. Smithsonian Institution Press, Washington and London.

Wu, C.-I., Li, W.H., 1985. Evidence for higher rates of nucleotide substitutions in rodents than in man. Proc. Natl. Acad. Sci. USA 82, $1741-1745$.

Wynne-Edwards, K.E., 2003. From dwarf hamster to daddy: the intersection of ecology, evolution, and physiology that produces paternal behavior. Adv. Study Behav. 32, 207-261.
Wynne-Edwards, K.E., Lisk, R.D., 1987. Behavioral interactions differentiate Djungarian (Phodopus campbelli) and Siberian (P. sungorus) hamsters. Can. J. Zool. 65, 2229-2235.

Yang, Z., 1996. Among-site rate variation and its impact on phylogenetic analyses. Trends Ecol. Evolut. 11, 367-372.

Yang, Z., 1997. PAML: a program package for phylogenetic analysis by maximum likelihood. Comput. Appl. Biosci. 13, 555-556.

Yang, Z., Rannala, B., 1997. Bayesian phylogenetic inference using DNA sequences: a Markov chain Montecarlo method. Mol. Biol. Evolut. 14, $717-724$.

Yigit, N., Çolak, E., Sözen, M., Özkurt, Ş, Verimli, R., 2000. The distribution, morphology, and karyology of the genus Mesocricetus (Mammalia: Rodentia) in Turkey. Folia Zool. 49, 167-174. 